\title{
Comparison of the Suppressive Effects of Elevated Plasma
}

\author{
Glucose and Free Fatty Acid Levels on Glucagon
}

\section{Secretion in Normal and Insulin-Dependent Diabetic Subjects}

\author{
EVIDENCE FOR SELECTIVE ALPHA-CELL INSENSITIVITY \\ TO GLUCOSE IN DIABETES MELLITUS
}

\author{
John E. Gerich, Maurice Langlois, Claudio Noacco, Mara Lorenzi, \\ John H. Karam, and Peter H. Forsham, with the technical assistance of \\ Gatr Gustafson \\ From the Metabolic Research Unit and Department of Medicine, University \\ of California, San Francisco, California 94143
}

A B S T R A T To examine whether abnormal pan-
creatic alpha-cell function found in human diabetes
mellitus may represent a selective insensitivity to glu-
cose, plasma glucagon responses to hyperglycemia and
elevation of plasma free fatty acid levels (both known
suppressors of glucagon secretion) were compared in
juvenile-onset, insulin-requiring diabetic subjects, and
in normal nondiabetic subjects. In the latter, both ele-
vation of plasma free fatty acid levels induced by heparin
administration and hyperglycemia produced by intra-
venous infusion of glucose resulted in a comparable
$30-40 \%$ suppression of circulating glucagon levels ( $P<$
0.01 ). In the diabetic subjects, glucagon suppression by
hyperglycemia ( $<20 \%$ ) was less than that occurring
in normal subjects ( $P<0.01$ ), even when accompanied
by infusion of supraphysiologic amounts of insulin.
However, suppression of glucagon levels by elevation
of plasma free fatty acids in the diabetic group was
similar to that found in normal subjects and of com-
parable magnitude to that due to hyperglycemia in the
normal subjects. These results thus demonstrate a se-
lective impairment of the diabetic alpha-cell response to
glucose and provide further evidence for the presence of

Dr. Langlois' present address is Centre Hospitalier Universitaire, Sherbrooke, Quebec, Canada.

Dr. Noacco's present address is Ospedale Civile Generale Regionale 33100 Udine, Italy.

Received for publication 12 January 1976 and in revised form 30 March 1976. an abnormal alpha-cell glucoreceptor in human diabetes mellitus.

\section{INTRODUCTION}

Two hypotheses have been proposed to explain pancreatic alpha-cell dysfunction in idiopathic human diabetes mellitus. One suggests that insulin lack per se is responsible $(1,2)$. This is supported by observations that hyperglucagonemia can develop secondarily to beta-cell destruction both in animals made diabetic experimentally with alloxan (3) and in humans with diabetes resulting from pancreatitis $(4,5)$. Moreover, acute insulin deprivation in diabetic humans $(6,7)$ and alloxan-diabetic dogs (8) results in hyperglucagonemia that can be reversed by insulin administration $(8,9)$. The other hypothesis proposes that idiopathic diabetes mellitus is a bihormonal disease $(10,11)$ in which abnormal glucagon secretion may result from a primary pancreatic alpha-cell insensitivity to glucose $(10,11)$ similar to that proposed to explain deficient diabetic pancreatic beta-cell function $(12,13)$. This proposal is supported by observations that the diabetic alpha cell responds inappropriately to both hyper- (14) and hypoglycemia (11) and that diabetic hyperglucagonemia is often found despite normal or elevated insulin levels (15).

Although glucose is probably the major substrate regulating glucagon secretion, free fatty acids (FFA) ${ }^{1}$

${ }^{1}$ Abbreviation used in this paper: FFA, free fatty acids. 
also influence pancreatic alpha-cell function. Elevation of plasma FFA levels suppresses glucagon secretion in several species (16-19), including man (20-22). Hyperglucagonemia and elevated plasma FFA levels coexist in diabetic ketoacidosis $(23,24)$, but it is unclear whether, under less stressful conditions and with only mild insulin deficiency, the suppressive effect of FFA on glucagon secretion is impaired in diabetes mellitus as is suppression by glucose. Since this question is important in determining whether the diabetic alpha cell is selectively insensitive to glucose, the present studies were undertaken to compare the suppressive effects of hyperglycemia and heparin-induced elevation of plasma FFA levels on glucagon secretion in normal nondiabetic subjects and in insulin-dependent diabetic subjects.

\section{METHODS}

Informed consent was obtained from six normal subjects (five men and one woman), 21-28 yr of age, who were not obese $\left(94-100 \%\right.$ ideal body weight $\left.{ }^{2}\right)$ and who had no family history of diabetes, and also from ten subjects with juvenile-onset diabetes mellitus (eight men and two women), aged 21-35 yr. None of the diabetic subjects were obese (91-102\% ideal body weight ${ }^{2}$ ), ketotic, or acutely ill at the time of study. The duration of their diabetes ranged from 7 to $28 \mathrm{yr}$, and their daily insulin requirements averaged 45-70 U.

All studies were begun between 7 and 8 a.m. with subjects in the postabsorptive state. Insulin was withheld from the diabetic subjects for at least $24 \mathrm{~h}$ before testing. Using 19-gauge butterfly needles, an infusion of saline solution $(0.45 \%)$ was begun in an antecubital vein of each armone for blood sampling, the other for administration of drugs. Subsequently, at least one-half hour was allowed for stabilization before collecting base-line blood specimens. Two protocols were used in random order. On one day, plasma FFA levels were elevated by i.v. administration of 3,000 U heparin (Riker Laboratories Inc., Northridge, Calif.; $1,000 \mathrm{U} / \mathrm{ml}$ ) as a $3-\mathrm{ml}$ bolus at 0,15 , and $30 \mathrm{~min}$; blood samples for glucose, FFA, and glucagon determinations were collected at $15-\mathrm{min}$ intervals over $90 \mathrm{~min}$. On another day, sustained hyperglycemia was induced by i.v. administration of glucose $(150 \mathrm{mg} / \mathrm{kg}$ as an initial bolus using $50 \%$ glucose, followed by an infusion of $0.3-0.5 \mathrm{~g} /$ $\mathrm{kg}$ per $\mathrm{h}$ of $20 \%$ glucose) for $2 \mathrm{~h}$ in the normal subjects, and glucose $(0.4-0.6 \mathrm{~g} / \mathrm{kg}$ per $\mathrm{h}$ as a $20 \%$ solution) plus insulin $(0.6 \mathrm{U} / \mathrm{kg}$ per $\mathrm{h}$; Eli Lilly and Co., Indianapolis, Ind.; U 100 regular Monocomponent) was infused for $6 \mathrm{~h}$ in the diabetic subjects. Blood samples for glucose and glucagon determinations were collected at $30-$ to $60-\mathrm{min}$ intervals over the respective experimental periods.

Plasma glucose, FFA, and glucagon levels were determined by methods previously described (20). Two-tailed Student's $t$ tests were used for statistical evaluation of data. Nonpaired tests were used for comparison of results from normal subjects with those of the diabetics; otherwise, paired tests were used.

\section{RESULTS}

Effect of elevation of plasma FFA levels on plasma glucagon in normal and juvenile-onset diabetic subjects

\footnotetext{
${ }^{2}$ Based on Metropolitan Life Insurance Company tables.
}

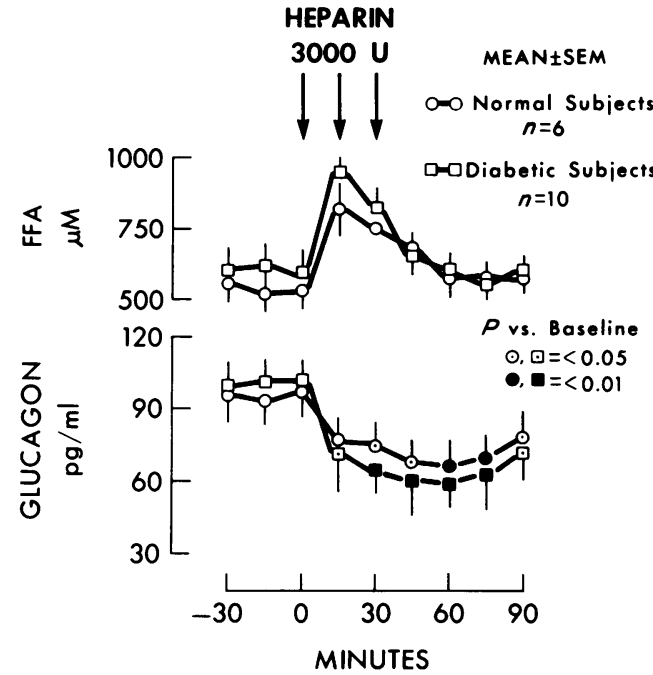

FIGURE 1 Effect of heparin-induced hyperlipidacidemia on plasma glucagon levels in normal and juvenile-onset diabetic subjects. Probability values refer to differences from their base line among individuals.

(Fig. 1). Administration of heparin resulted in comparable elevation of plasma FFA levels in normal and diabetic subjects. Plasma FFA rose from a mean ( $\pm \mathrm{SE}$ ) basal level of $540 \pm 56 \mu \mathrm{M}$ to a peak value of $813 \pm 83 \mu \mathrm{M}$ at $15 \mathrm{~min}$ in the normal subjects $(P<$ 0.01 ) and from $600 \pm 63$ to $951 \pm 46 \mu \mathrm{M}$ at $15 \mathrm{~min}$ in the diabetic subjects $(P<0.01)$. Thereafter, despite repeated heparin administration, FFA levels gradually returned toward base-line values in both groups. Basal plasma glucose levels averaged $84 \pm 2 \mathrm{mg} / 100 \mathrm{ml}$ in the normal subjects and $297 \pm 30 \mathrm{mg} / 100 \mathrm{ml}$ in the diabetic subjects. No significant changes in these values or in insulin levels (measurable only in the normal subjects because of the presence of insulin antibodies in the diabetics) were observed.

After heparin administration, plasma glucagon levels declined similarly in both groups, falling progressively in the normal subjects from a mean basal level of $94 \pm$ $10 \mathrm{pg} / \mathrm{ml}$ to a nadir of $66 \pm 11 \mathrm{pg} / \mathrm{ml}$ at $60 \mathrm{~min}(P<$ $0.01)$. Thereafter, levels rose toward baseline, reaching $77 \pm 11 \mathrm{pg} / \mathrm{ml}$ at $90 \mathrm{~min}$. In the diabetic subjects, plasma glucagon fell slightly more rapidly from a mean basal level of $99 \pm 9$ to $69 \pm 14 \mathrm{pg} / \mathrm{ml}$ at $15 \mathrm{~min}(P<0.05)$ and to a nadir of $60 \pm 12 \mathrm{pg} / \mathrm{ml}$ at $60 \mathrm{~min}(P<0.01)$. Thereafter, levels rose toward baseline, reaching $70 \pm$ $10 \mathrm{pg} / \mathrm{ml}$ at $90 \mathrm{~min}$. These results indicate that, in diabetes mellitus, glucagon suppression after heparin-induced elevation of plasma FFA levels is similar to that found in nondiabetic individuals.

Effect of hyperglycemia and insulin on plasma glucagon levels in normal and juvenile-onset diabetic subjects (Fig. 2). Despite fasting hyperglycemia (plasma 


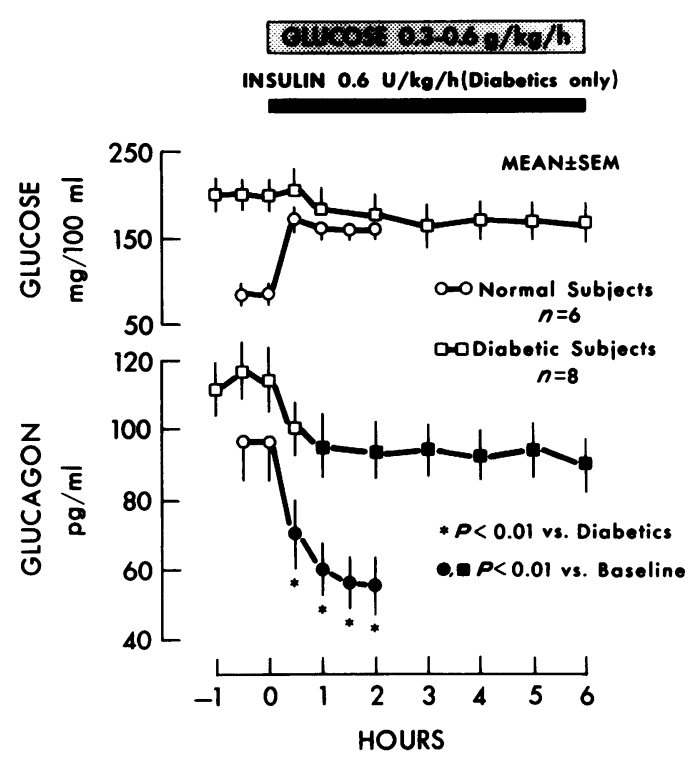

FIGURE 2 Effect of hyperglycemia on plasma glucagon levels in normal and juvenile-onset diabetic subjects. Normal subjects were infused with glucose alone; the diabetic subjects received glucose plus insulin.

glucose levels averaging $202 \pm 17 \mathrm{mg} / 100 \mathrm{ml}$ ), plasma glucagon levels in the diabetic subjects $(114 \pm 10 \mathrm{pg} / \mathrm{ml})$ were similar to those found in the normal subjects $(96 \pm$ $11 \mathrm{pg} / \mathrm{ml}$ ). A previous study (14) had indicated that this relative hyperglucagonemia is not normalized by infusion of pharmacologic amounts of insulin for as long as $3 \mathrm{~h}$. However, it is unclear whether appropriate alpha-cell responses to glucose might have occurred if insulin had been infused for a longer period of time. Therefore, to study this question and to compare the acute effects of hyperglycemia in the presence of insulin

\section{DIABETIC SUBJECTS NORMAL SUBJECTS} $n=8$
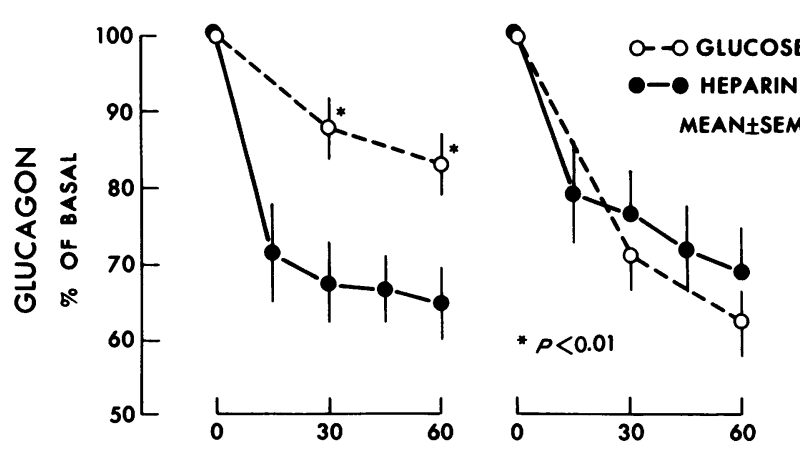

MINUTES

FIGURE 3 Comparison of pancreatic alpha-cell suppression by hyperlipidacidemia and hyperglycemia in normal and juvenile-onset diabetic subjects. Results are derived from data in Figs. 1 and 2. in diabetic and normal subjects, glucose and sufficient insulin to generate circulating insulin levels in excess of $1,000 \mu \mathrm{U} / \mathrm{ml}$ (14) were infused into the diabetics over $6 \mathrm{~h}$, and sufficient glucose to produce comparable hyperglycemia was infused into the normal subjects over $2 \mathrm{~h}$.

Plasma glucose levels declined slightly in the diabetic subjects during the initial $3 \mathrm{~h}$ to $166 \pm 33 \mathrm{mg} / 100$ $\mathrm{ml}$ but remained stable thereafter. Comparable hyperglycemia was produced in the normal subjects: plasma glucose levels averaged between 161 and $172 \mathrm{mg} / 100 \mathrm{ml}$ and serum insulin levels (data not shown) averaged between 35 and $48 \mu \mathrm{U} / \mathrm{ml}$ during the 2 -h glucose infusion. In both groups, plasma glucagon levels declined significantly $(P<0.01)$ within $1 \mathrm{~h}$, but greater decrements to significantly lower absolute levels $(P<0.01)$ occurred in the normal subjects: In the diabetics, plasma glucagon declined from a mean base-line value of $114 \pm 10$ to $95 \pm 10 \mathrm{pg} / \mathrm{ml}$ at $1 \mathrm{~h}(P<0.01)$ and remained approximately at this level during the rest of the glucose/ insulin infusion, averaging $90 \pm 8 \mathrm{pg} / \mathrm{ml}$ at $6 \mathrm{~h}$; in the normal subjects, plasma glucagon fell abruptly from a mean base-line value of $96 \pm 11$ to $70 \pm 11 \mathrm{pg} / \mathrm{ml}$ at 30 $\min (P<0.01)$ and to a nadir of $55 \pm 9 \mathrm{pg} / \mathrm{ml}$ at $2 \mathrm{~h}$ $(P<0.01)$. The glucagon levels of the normal subjects $(55-60 \mathrm{pg} / \mathrm{ml})$ became significantly lower $(P<$ $0.01)$ than those of the diabetic subjects $(90-95 \mathrm{pg} /$ $\mathrm{ml})$ at all sampling times after infusing glucose for $1 \mathrm{~h}$. Thus, acute administration of pharmacologic amounts of insulin for $6 \mathrm{~h}$ definitely lowered glucagon levels in the diabetic subjects, but it did not normalize their alphacell response to hyperglycemia.

Comparison of glucagon suppression by elevation of plasma FFA levels and by hyperglycemia in normal and juvenile-onset diabetic subjects (Fig. 3). 8 of the 10 diabetic subjects studied participated in both experiments. Their paired glucagon responses during the initial hour of each suppressive maneuver are compared in Fig. 3 with those of the six normal subjects who participated in both experiments. Plasma glucagon levels were suppressed to a similar degree by hyperglycemia and by elevation of plasma FFA levels in the normal subjects, whereas in the diabetic subjects elevation of plasma FFA levels resulted in significantly greater suppression $(P<0.01$ at 30 and $60 \mathrm{~min})$ than did hyperglycemia. Thus, under the present experimental conditions, the diabetic pancreatic alpha cell was selectively insensitive to glucose, even in the presence of supraphysiologic circulating levels of insulin.

\section{DISCUSSION}

In normal man, elevation of either plasma glucose or plasma FFA levels suppresses glucagon secretion $(10,14$, 20-22). In individuals with diabetes mellitus, however, the ability of glucose to suppress glucagon secretion is impaired $(10,14,25)$. It has been suggested that this 
phenomenon may represent an intrinsic alpha-cell glucoreceptor abnormality independent of insulin deficiency $(10,11,26)$. The present studies were undertaken to test this hypothesis. Firstly, the effect of acute elevation of plasma FFA on circulating glucagon levels was compared in diabetic and normal subjects to determine whether diabetic alpha-cell hyporesponsiveness was limited to glucose as a suppressant; secondly, the effect of pharmacologic amounts of exogenous insulin on glucoseinduced suppression of glucagon secretion was studied to determine whether insulin replenishment could normalize diabetic alpha-cell responses to glucose.

Acute elevation of plasma FFA after heparin administration resulted in comparable suppression of circulating glucagon levels in diabetic and normal subjects. This finding thus precludes a generalized insensitivity of the diabetic alpha cell to suppression by metabolic substrates and provides additional evidence that the diabetic alpha cell may be selectively insensitive to modulation by glucose. Of interest is the observation that, in the normal subjects, no change in plasma glucose levels occurred during suppression of glucagon secretion by elevation of plasma FFA. One would have expected glucose levels to decline during suppression of glucagon secretion in the face of continued insulin secretion because plasma glucose levels fall in normal individuals during the simultaneous inhibition of insulin and glucagon secretion by somatostatin (27). This apparent discrepancy can be explained, however, by studies $(16,28)$ demonstrating that, during elevation of circulating FFA, diminution in hepatic glucose production is counterbalanced by an equivalent diminution in peripheral glucose utilization so that no net change in circulating glucose levels is observed.

In the present study, infusion of pharmacologic amounts of insulin for $6 \mathrm{~h}$ improved, but did not normalize, diabetic alpha-cell suppressibility by hyperglycemia. Two previous studies $(14,25)$ have examined the effects of exogenous insulin on suppression of plasma glucagon by glucose in human diabetics. Both found that, when suppression in the diabetics was compared with that in normal subjects made hyperglycemic by infusion of glucose alone (14) or glucose plus comparable amounts of insulin (25), suppression in the diabetics was still impaired.

In the study of Raskin et al. (25), suppression of glucagon levels by insulin in diabetics was similar to that occurring in normal subjects when very high doses of insulin (producing circulating insulin levels of 500 $600 \mu \mathrm{U} / \mathrm{ml}$ ) were infused into the diabetics. The reason is not clear for the discrepancy between these results and those of the present study in which normalization of glucose-induced glucagon suppression in diabetics was not achieved despite infusion of larger doses ( 0.6 vs. $0.4 \mathrm{U} / \mathrm{kg}$ per $\mathrm{h}$ ) of insulin for a longer period
(6 vs. $2 \mathrm{~h}$ ), but differences in design (normal subjects received only glucose in the present study) and the fact that normal and diabetic subjects were not comparably hyperglycemic in the Raskin study (diabetics were more hyperglycemic) might be important. Nevertheless, while both studies indicate that the diabetic alpha cell is responsive to insulin, both also suggest that insulin lack may not be solely responsible for diabetic hyperglucagonemia.

The fact that acute elevation of plasma FFA levels was able, in the present studies, to suppress plasma glucagon normally in the same diabetic individuals in whom hyperglycemia was a relatively ineffective suppressive agent indicates a selective insensitivity to glucose for the diabetic pancreatic alpha cell. The mechanism responsible for this phenomenon is unclear. It has been postulated that glucose regulates pancreatic alpha- and beta-cell function primarily by means of membrane glucoreceptors (29-31). Several lines of evidence indicate that these postulated glucoreceptors function abnormally in diabetes mellitus $(12,13,32,33)$. Previous observations of selective pancreatic beta-cell insensitivity to glucose $(13,32)$ are analogous to the findings of the present study with respect to diabetic alpha-cell responses to glucose. The diabetic alpha cell does not respond appropriately to either hyper- (14) or hypoglycemia (11) but does respond normally to changes in plasma FFA levels, indicating a defect apparently specific for glucose. Thus, abnormal glucagon and insulin secretion in diabetes mellitus might both be due to glucoreceptor dysfunction.

Whether these abnormalities could be the result of a single process (e.g., virus-induced membrane alteration), or whether one is primary and one secondary, is unclear. Abnormal glucagon secretion in human diabetes may represent an alpha-cell glucoreceptor malfunction different from the beta-cell glucoreceptor malfunction causing diminished insulin secretion. For example, suppression of glucagon secretion by FFA may not require insulin, whereas appropriate glucagon responses to glucose might demand conditioning of the alpha-cell glucoreceptor by insulin. Lack of insulin due to a primary beta-cell glucoreceptor defect could thus induce a secondary alpha-cell glucoreceptor abnormality.

Although the present results and those of Raskin et al. (25) indicate that insulin may play an important role in modulating glucagon secretion in diabetes, it should be pointed out that demonstration of an inhibitory effect on glucagon secretion of pharmacologic but not physiologic amounts of insulin would tend to militate against insulin lack being primarily responsible for abnormal alpha-cell function in human diabetes. Indeed, the recent findings of Pagliara et al. (34) that glucose could appropriately suppress glucagon release from perfused 
pancreases of alloxan- and streptozotocin-diabetic rats in the absence of insulin support this view. Their results indicate that hyperglucagonemia secondary to insulin lack induced by experimental beta-cell destruction is associated with normal alpha-cell glucoreceptors. Since insulin can diminish glucagon secretion in both this form of experimental diabetes $(3,8)$ and in spontaneous human diabetes $(9,14,24,25)$, this action of insulin may be independent of an effect on glucoreceptors. Thus, demonstration of an inhibitory effect of pharmacologic amounts of insulin on glucagon secretion need not exclude an intrinsic alpha-cell glucoreceptor defect. It should be emphasized that this action may be an important mechanism by which therapeutic administration of insulin improves diabetic control.

\section{ACKNOWLEDGMENTS}

This work was supported in part by grants from The Levi J. and Mary C. Skaggs Foundation, Oakland, Calif., The Susan Greenwall Foundation of New York City, and the Ellis L. Phillips Foundation of Jericho, N. Y. Investigations were carried out at the General Clinical Research Center, University of California, San Francisco, with funds provided by the Division of Research Resources (RR-79), U. S. Public Health Service.

\section{REFERENCES}

1. Buchanan, K. D., and A. M. McCarroll. 1972. Abnormalities of glucagon metabolism in untreated diabetes mellitus. Lancet. 2: 1394-1395.

2. Marks, V. 1972. Glucagon. Clinics in Endocrinology and Metabolism. (Lond.). 2: 829-844.

3. Müller, W. A., G. R. Faloona, and R. H. Unger. 1971. The effects of experimental insulin deficiency on glucagon secretion. J. Clin. Invest. 50: 1992-1999.

4. Buchanan, K. D. 1973. Pancreatic glucagon in diabetes mellitus and chronic pancreatitis. Postgrad. Med. J. 49: 604-606.

5. Kalk, W. J., A. I. Vinik, S. Bank, K. D. Buchanan, P. Keller, and W. P. U. Jackson. 1974. Glucagon responses to arginine in chronic pancreatitis: possible pathogenic significance in diabetes. Diabetes. 23: 257-263.

6. Gerich, J. E., E. Tsalikian, M. Lorenzi, J. H. Karam, and D. M. Bier. 1975. Plasma glucagon and alanine responses to acute insulin deficiency in man. J. Clin. Endocrinol. Metab. 40: 526-529.

7. Alberti, K. G. M. M., N. J. Christensen, J. Iversen, and H. Orskov. 1975. Role of glucagon and other hormones in development of diabetic ketoacidosis. Lancet. 1: 1307-1311.

8. Braaten, J. T., G. R. Faloona, and R. H. Unger. 1974. The effect of insulin on the alpha-cell response to hyperglycemia in long-standing alloxan diabetes. J. Clin. Invest. 53 : 1017-1021.

9. Gerich, J. E., E. Tsalikian, M. Lorenzi, V. Schneider, N. V. Bohannon, G. Gustafson, and J. H. Karam. 1975. Normalization of fasting hyperglucagonemia and excessive glucagon responses to intravenous arginine in human diabetes mellitus by prolonged infusion of insulin. J. Clin. Endocrinol. Metab. 41: 1178-1180.

10. Unger, R. H. 1971. Glucagon physiology and pathophysiology. N. Engl. J. Med. 285: 443-449.
11. Gerich, J. E., M. Langlois, C. Noacco, J. H. Karam, and P. H. Forsham. 1973. Lack of glucagon response to hypoglycemia in diabetes: evidence for an intrinsic pancreatic alpha cell defect. Science (Wash. D. C.). 182: 171-173.

12. Cerasi, E., R. Luft, and S. Efendic. 1972. Decreased sensitivity of the pancreatic beta cells to glucose in prediabetic and diabetic subjects: a glucose dose-response study. Diabetes. 21 : 224-234.

13. Robertson, R. P., and D. Porte, Jr. 1973. The glucose receptor: a defective mechanism in diabetes mellitus distinct from the beta adrenergic receptor. J. Clin. Invest. $52: 870-876$.

14. Unger, R. H., L. L. Madison, and W. A. Müller. 1972. Abnormal alpha cell function in diabetics: response to insulin. Diabetes. $21: 301-307$.

15. Unger, R. H., E. Aguilar-Parada, W. A. Müller, and A. M. Eisentraut. 1970. Studies of pancreatic alpha cell function in normal and diabetic subjects. J. Clin. Invest. 49 : 837-848.

16. Seyffert, W. A., Jr., and L. L. Madison. 1967. Physiologic effects of metabolic fuels on carbohydrate metabolism. I. Acute effect of elevation of plasma free fatty acids on hepatic glucose output, peripheral glucose utilization, serum insulin, and plasma glucagon levels. Diabetes. 16 : 765-776.

17. Luyckx, A. S., and P. J. Lefebvre. 1970. Arguments for a regulation of pancreatic glucagon secretion by circulating plasma free fatty acids. Proc. Soc. Exp. Biol. Med. 133: 524-528.

18. Edwards, J. C., and K. W. Taylor. 1970. Fatty acids and the release of glucagon from isolated guinea-pig islets of Langerhans incubated in vitro. Biochim. Biophys. Acta. 215 : 310-315.

19. Gross, R., and P. Miahle. 1974. Free fatty acid-glucagon feed-back mechanism. Diabetologia. 10: 277-283.

20. Gerich, J. E., M. Langlois, V. Schneider, J. H. Karam, and C. Noacco. 1974. Effects of alterations of plasma free fatty acid levels on pancreatic glucagon secretion in man. J. Clin. Invest. 53: 1284-1289.

21. Andrews, S. S., A. Lopez-S., and W. G. Blackard. 1975. Effect of lipids on glucagon secretion in man. Metab. Clin. Exp. 24: 35-44.

22. Luyckx, A. S., J. Gerard, U. Gaspard, and P. J. Lefebvre. 1975. Plasma glucagon levels in normal women during pregnancy. Diabetologia. 11 : 549-554.

23. Assan, R., G. Hautecouverture, S. Guillemant, F. Dauchy, P. Protin, and M. Derot. 1969. Evolution de paramètres hormonaux (glucagon, cortisol, hormone somatotrope) et énergétiques (glucose, acides gras, glycérol libre) dans dix acido-cétoses diabétiques graves traitées. Pathol. Biol. 17: 1095-1105.

24. Müller, W. A., G. R. Faloona, and R. H. Unger. 1973. Hyperglucagonemia in diabetic ketoacidosis: its prevalence and significance. Am. J. Med. 54: 52-57.

25. Raskin, P., Y. Fujita, and R. H. Unger. 1975. Effect of insulin-glucose infusions on plasma glucagon levels in fasting diabetics and nondiabetics. J. Clin. Invest. 56: 1132-1138.

26. Niki, A., and H. Niki. 1975. Is diabetes mellitus a disorder of the glucoreceptor? Lancet. 2: 658.

27. Gerich, J. E., M. Lorenzi, S. Hane, G. Gustafson, R. Guillemin, and P. H. Forsham. 1975. Evidence for a physiologic role of pancreatic glucagon in human glucose homeostasis: studies with somatostatin. Metab. Clin. Exp. 24 : 175-182. 
28. Balasse, E. O., and M. A. Neef. 1974. Operation of the "glucose-fatty acid cycle" during experimental elevations of plasma free fatty acid levels in man. Eur. J. Clin. Invest. 4 : 247-252.

29. Randle, P. J., and C. N. Hales. 1972. Insulin release mechanisms. Handb. Physiol. Section 7. Endocrinology. $1:$ :219-235.

30. Grodsky, G. M., R. Fanska, L. West, and M. Manning. 1974. Anomeric specificity of glucose-stimulated insulin release: evidence for a glucoreceptor? Science (Wash. D. C.). 186 : 536-538.

31. Matschinsky, F. M., A. S. Pagliara, B. A. Hover, M. W. Haymond, and S. N. Stillings. 1975. Differential effects of $\alpha$ - and $\beta$-D-glucose on insulin and glucagon secretion from the isolated perfused rat pancreas. Diabetes. 24 : 369-372.

32. Deckert, T., U. B. Lauridsen, S. N. Madsen, and P. Mogensen. 1972. Insulin response to glucose, tolbutamide, secretin, and isoprenaline in maturity-onset diabetes mellitus. Dan. Med. Bull. 19: 222-226.

33. Halter, J., P. Kulkosky, S. Woods, W. Makous, M. Chen, and D. Porte, Jr. 1975. Afferent receptors, taste perception, and pancreatic endocrine function in man. Diabetes. 24 : 414 . (Abstr.)

34. Pagliara, A. S., S. N. Stillings, M. W. Haymond, B. A. Hover, and F. M. Matschinsky. 1975. Insulin and glucose as modulators of the amino acid-induced glucagon release in the isolated pancreas of alloxan and streptozotocin diabetic rats. J. Clin. Invest. 55: 244-255. 